\title{
The Impact of Child Abuse in Kwekwe District Secondary Schools in Zimbabwe
}

\author{
Wilard Nyathi* \\ Faculty of Education: AMADI University \\ *Corresponding Author: Wilard Nyathi, Faculty of Education: AMADI University

\begin{abstract}
Cases of child abuse are reported year in and year out in Zimbabwe with little signs of the phenomenon abating. Child abuse is when a parent, caregiver, adult, sibling, classmate or any other person more powerful than the victim, whether through action or failing to act, causes injury, death, emotional harm or risk of serious harm to a child. Child abuse usually refers to unfair, cruel or violent treatment of a child in a physical, sexual and emotional way, including child labour such that the victim's rights are threatened and for school children, it significantly affects their learning. The study employed the quantitative methodology using a sample of 800 form three and form four pupils randomly selected from the thirty secondary schools in Kwekwe District of Zimbabwe's Midlands Education Province. The study utilised the questionnaire to collect data from the respondents. The study revealed that child abuse was prevalent in Kwekwe District and yet most school authorities were not doing enough to eradicate it. Most of the students in the sample had themselves been victims of one form of abuse or the other. The researcher recommends that school heads, teachers, pupils and parents should work together to expose, prevent and report all cases of abuse of children to avoid emotional and physical damage to the children.
\end{abstract}

Key words: Cases, child abuse, impact, performance of pupils, district.

\section{INTRODUCTION}

Child abuse is exposing children to painful and unwarranted suffering knowingly or unknowingly (Holt and Finkelhor, 2007). In Zimbabwe, child abuse has become an apparent endless vicious cycle that destroys the lives of many young people (Rupapa, 2016). Many adults are in the habit of abusing children without considering the effects of that treatment on the children. According to Denga and Denga (2007) in the year 2016 alone, Zimbabwe reported more than 12000 cases of child abuse. These statistics show a frightening increase in the number of children who are abused by adults and need assistance from different stakeholders from the wider community (Ndlovu, 2016).

Research reveals that child abuse can have negative effects on a child's academic performance as well as their future adult life (Murimba, 2009). There are many students who experience abuse in Zimbabwean homes, schools and workplaces, and this is reflected on their school performance (Moyo, 2015). Child abuse is an utterly intolerable violation of children's rights. As Kavishe (2016) posits, "At a time when Zimbabweans are making phenomenal efforts to absorb more than one million orphans, there appears a small number of us, who prey on the most vulnerable of children". Everyday there are fresh reports in the local media about children being abused; sometimes at their schools, other times by family members, but almost always by figures of authority, trusted figures (Kavishe, 2016). Fears of reprisal and families' willingness to reach settlements deepen a culture of silence and enable the problem to fester undetected and unreported and for the sake of the children this cannot continue (Moyo, 2015).

Action Aid Zimbabwe (2016) revealed that more than $80 \%$ of pupils who drop out from secondary schools in Zimbabwe do so as a result of one form of child abuse or the other. Although there have been initiatives such as Child Protection Committees (CPCs) formed at both community and school levels to deal with challenges facing children, these structures have been falling short as there is too much involvement of adults (Action Aid Zimbabwe, 2016) and most cases of child abuse have been swept under the carpet by the adults who claim to be child rights watchdogs. It is on account of this background that this study sought to assess the prevalence of child abuse in secondary schools and how it affected their academic performance from the perspectives of the victims or potential victims; the children themselves. 


\section{LITERATURE REVIEW}

Child abuse includes all types of physical emotional ill-treatment, sexual abuse, neglect and negligence which result in potential harm to the children's development or dignity (Shonk and Ciccheti, 2011). Dodge and Pettit (2004) view child abuse as an act of commission or omission on the part of the parent, guardian or caretaker that results in non-accidental, physical, mental injury or sex abuse. From these definitions, it becomes clear that child abuse refers to unfair, cruel or violent treatment of a child in a physical, sexual and emotional way including child labour such that the victim's rights are threatened (Iverson and Segal, 2009). Carlson and Kashami (2008) postulate that child abuse causes psychological problems, significant disruptions in the normal development and often have a lasting impact in leading dysfunction and distress well into adulthood. According to Anderson (2015) child abuse normally happens in a family which is characterised by conflict and domestic violence. Children sometimes grow up in such families with the understanding that such an arrangement is normal (Wood, 2008). Dysfunctional families are primarily a result of co-dependent adults and may be affected by addictions such as substance abuse (Mpofu, 2016). As Makoni (2016) argues, there is too much extremes in fighting and arguing and children are forced to take sides in conflicts between parents; they are ignored, discounted or criticised for their feelings and thoughts. Children have demands placed on their time, choice of friends or behaviour and they may receive no guidance from the parents at all; and this inhibits the development of the children's trust in the world, others, and in themselves and ultimately, they face problems in their academic work and in their relationships (Wood, 2008).

According to Smith (2014) child abuse is associated with the social learning theory which postulates that behaviour is learnt through two methods; being rewarded for actions and observing and imitating behaviour. Researchers believe that abused children learn to be abusive using these two methods and continue their abusive behaviour into adulthood (Reyome, 2013; Smith, 2014; Wood, 2008 and Moyo, 2016). This pattern of learned aggression is commonly referred to as "circle of violence" which means that abusers are likely to have been abused when they were young (Moyo, 2016). Sometimes child neglect is more likely to be caused by risk factors that a parent or caregiver may or may not be able to directly influence (Wood, 2008). It has been observed that families living in poverty may be unable to provide adequate nutrition, education or medical care for their children due to lack of access to resources not because they do not recognise their children's needs (Carlson and Kashami, 2008).

Studies show that children who have suffered from neglect exhibit lower academic achievement; mistreated children have a greater instance of exhibiting poor social skills and classroom behaviour problems (CASA, 2015). Mapolisa (2015) further posits that, maltreatment in the first five years of life nearly triples a child's likelihood of having academic problems. CASA (2015) states that according to research, children with special educational needs are more than seven times more likely to suffer physical abuse and neglect; and that this causes lower academic success which can cause lifelong, negative psychological and economic consequences.

Livege and Poipoi (2012) found that pupils who were involved in child labour had a significantly lower academic achievement mean score than those not involved. Mfonobong (2013) in his study of "Child Abuse and its implications for the Educational Sector in Nigeria", argues that child abuse has serious implications on the educational system in Nigeria and it presents a serious draw back on the child educational development and thus, hinders societal growth and development. The problem of child abuse in the education systems requires adequate and efficient handling in order to improve educational development.

\subsection{Statement of the Problem}

The prevalence of child abuse in Zimbabwe is a very worrying issue because the phenomenon of child abuse itself, denotes treating children as sub-humans and actually a violation of their rights. Secondly, the magnitude of this type of abuse is difficult to determine, because only a few cases of its presence are reported and in most cases by adults and not by the victims themselves (children). This therefore, means that this prevalence though a disturbing situation is just the tip of the iceberg. Since it has the potential to affect many children, child abuse is most likely to affect the performance of the affected children in their school work in a very big way, and thus needs to be curtailed at all costs.

\subsection{Purpose of the Study}

The purpose of this empirical study was to investigate and expose the magnitude of the prevalence of child abuse in secondary schools in order to come up with practical measures to mitigate the impact of 
this phenomenon on the learning of the victims and also to avoid more cases of child abuse in the homes and in the schools.

\subsection{Significance of the Study}

The significance of this study stems from the fact that it sought to get first hand information from the victims and potential victims of child abuse themselves. A number of studies have been carried out on this phenomenon and most of them, if not all, collected or generated their data from adults in the form of teachers, parents and / or community leaders. Literature on information from children in the schools is relatively thin, and thus, this study hopes to contribute in a small way to reduce that gap.

\subsection{Delimitation}

The study delimited itself to the assessment of cases of child abuse and their impact on performance of secondary school pupils in Kwekwe District in Zimbabwe's Midlands Province. The study utilised the quantitative methodology and adopted the random sampling technique to arrive at a sample of 800 pupils. Form three and form four pupils were used in this study. Pupils from other forms, teachers, heads of schools, parents, police, nurses and other community members were outside the purview of this study.

\subsection{Limitations}

School authorities would naturally not be very excited to have external researchers investigating their pupils without their involvement (school authorities), especially on a subject that may have the potential to implicate them one way or the other. It took a lot of explanations to convince the Ministry of Primary and Secondary Education authorities about the intentions of the study which actually hoped to complement their sterling work in providing quality education to their pupils with minimum distractions.

The other major limitation of the study was a result of the quantitative methodology employed. The study employed the descriptive survey method which according to Ary and Razaviah (2010) lacks predictive power since the research may discover and describe "what is" and unable to predict "what would be". In view of the small size of the sample size used, the findings of the study would have limited generalisability. Respondents could also have given false responses thereby affecting the validity of the findings, especially on a sensitive topic like 'child abuse' as they may have feared exposure and victimisation. The researcher mitigated this limitation by assuring the pupils of absolute anonymity.

\section{Methodology}

The study used the quantitative methodology and made use of a survey research design. According to Leedy (2009), the descriptive survey method looks with intense accuracy at the phenomenon of the moment and then describes precisely what the researcher sees. The questionnaire was used as the instrument for collecting data because as Flick (2009) postulates, it can be analysed more scientifically and objectively than other forms of research. Positivists also believe that quantitative data can be used to create new theories and / or test existing hypotheses (Glensen and Peshkin, 2012). The questionnaire was also used because it increases reliability as an instrument of gathering data because of its greater impersonality.

\subsection{Data Collection and Analysis}

As alluded to above, data were gathered by means of a questionnaire which was comprised of both close-ended and open-ended questions. The language used in the questionnaire was made very simple and clear for the level of the respondents (form 3 and form 4 pupils). The instrument was pilot tested with 50 pupils at one secondary school in the district in order to ensure the questions were understood by the respondents and that there were no problems with the wording or measurement (Mackenzie and Knipe, 2006). Pilot testing also helped to identify potential problems with the methods, logistics and the questionnaire. Inspite of its many advantages the questionnaire has some limitations which the researcher took into account. For example, as Cresswell (2009) posits, the questionnaire may yield a low response rate and is inflexible in that it does not allow ideas or comments to be explored in-depth and many questions may remain unanswered. This was partly mitigated by pilot testing as highlighted earlier on. The researcher personally distributed the questionnaires to the schools understudy and the same method was used to collect the completed questionnaires in order to 
maximise on the rate of return of the instrument. Non-returns, as Marshall and Rossman (2006) argue, introduce a bias in as much as they are likely to differ in many ways from respondents thereby affecting reliability and validity. Data produced from the questionnaire yielded descriptive statistics around the variables understudy. These statistics were computed and presented in tables, graphs and figures and discussed and analysed in the following section.

\subsection{Findings and Discussion}

The study set out to assess the prevalence of cases of child abuse and its impact on the performance of pupils in secondary schools in Kwekwe District in Zimbabwe. This section is presented in two parts namely presentation of data and discussion.

\subsection{Presentation of Data}

Table1. Demographic characteristics of respondents by $\operatorname{sex}(N=800)$

\begin{tabular}{|l|l|l|}
\hline Sex & Frequency & Percentage \\
\hline Male & 376 & 47 \\
Female & 424 & 53 \\
\hline Total & $\mathbf{8 0 0}$ & $\mathbf{1 0 0}$ \\
\hline
\end{tabular}

The data on Table 1 above shows that 47 percent of the respondents were male and 53 percent were female. Since the researcher utilised the simple random sampling technique, the above composition of respondents in the sample by sex is a reflection of the actual composition of pupils by sex in most Zimbabwean schools. This is corroborated by Makoni (2016) who found that most schools in Zimbabwe have more girls than boys (52 percent girls against 48 percent boys). This information is therefore considered statistically significant in that it reflects the accurate composition of pupils by sex in secondary schools.

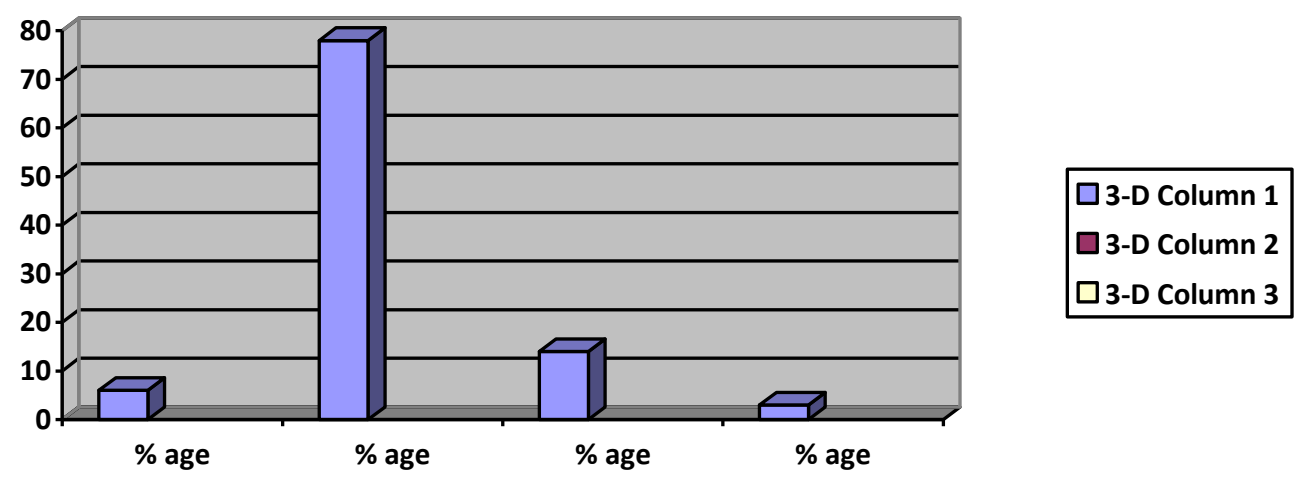

Figure1. Demographic characteristics of respondents by age-range $(N=800)$

The bar graph above (Figure 1), shows the age distribution of students who participated in the study. It reveals that the bulk of the respondents (78\%) fell within the 15-16 years' age range. The other age ranges had insignificant number of students (12-14: 6\%; 17-18: 14\% and 19-20: $3 \%$ respectively). The respondents were doing form three and form four and it comes as no surprise that most of them fall within the 15-16 years' age group since most children in Zimbabwe join primary school either at age six or age seven; which means they are between 15 and 16 years by the time they reach form three and form four.

Table2. Responses to the question: "Which are the most common forms of child abuse in your school and community?" $(N=800)$

\begin{tabular}{|l|l|l|}
\hline Response category & Frequency & Percentage \\
\hline Failure to pay fees & 616 & 77 \\
Physical abuse / Corporal punishment & 760 & 95 \\
Verbal abuse & 794 & 98 \\
Hunger & 608 & 76 \\
Missing parents & 520 & 65 \\
Fighting parents & 472 & 59 \\
Violent teachers & 792 & 99 \\
\hline
\end{tabular}




\begin{tabular}{|l|l|l|}
\hline Sexual abuse & 304 & 48 \\
Bullying & 800 & 100 \\
\hline
\end{tabular}

The information on Table 2 above reveals that there are many forms of child abuse perpetrated against secondary school pupils. All the forms of abuse exist in high frequencies with bullying (100\%), violent teachers (99\%), verbal abuse (98\%) and physical abuse / corporal punishment toping this list. The other forms may be lower than the top four, but non the less, they to exist in quite high frequencies. For example, failure to pay fees stood at 77 percent, hunger at 76 percent, missing parents stood at $65 \%$, fighting parents at 59 percent, and finally, sexual abuse at 48 percent respectively.

Table3. Responses to the question: "Who is most likely to abuse you and how? $(N=800)$

\begin{tabular}{|l|l|l|l|}
\hline Perpetrator & Nature of abuse & Frequency & Percentage \\
\hline Parents / Guardians & $\begin{array}{l}\text { Failure to pay fees; beating me; failing to give } \\
\text { me pocket money; rebuking me in strong } \\
\text { language; overworking me before and after } \\
\text { school; hate my friends; fighting each other in } \\
\text { front of me. }\end{array}$ & 680 & 85 \\
\hline Teachers & $\begin{array}{l}\text { Beating me; rebuking me in strong language; } \\
\text { fondling me; forcing me to love him }\end{array}$ & 664 & 83 \\
\hline Siblings & $\begin{array}{l}\text { Hate my friends; insult each other; insult me; } \\
\text { send me to buy drugs }\end{array}$ & 520 & 65 \\
\hline Bullies & $\begin{array}{l}\text { Beating me; force me to love them; fondle me; } \\
\text { send me to buy drugs and force me to use them; } \\
\text { take my pocket money by force }\end{array}$ & 800 & 100 \\
\hline
\end{tabular}

Table 3 above shows the people likely to perpetrate various forms of abuse to children and the nature of abuse associated with these perpetrators. Respondents mentioned bullies as the highest perpetrators of their abuse (100\%). Bullies were said to beat other children; force them to love them and force them to use drugs. Parents were cited by the second largest number of respondents as also likely to abuse them (85\%) through various ways. Parents / Guardians abused children by failing to pay their fees on time; hated their friends (children's) and fought in front of the children. Teachers came third at (83\%) as perpetrators of abuse against children through beating them; rebuking; forced love affairs and fondling them. Finally, a large number of respondents $(65 \%)$ also cited their siblings as perpetrators of their abuse.

Table4. Responses to the question: "How does child abuse affect the victim in their school work? $(N=800)$

\begin{tabular}{|l|l|l|}
\hline Category of responses & Frequency & Percentage \\
\hline Sleeping in class & 120 & 15 \\
Absenteeism and unwritten work & 192 & 24 \\
Violent and abusive language & 64 & 8 \\
Quiet and shy & 80 & 10 \\
Reserved and timid & 56 & 7 \\
Failure to concentrate & 80 & 10 \\
Low marks & 160 & 20 \\
Stealing & 24 & 3 \\
Fondling girls & 24 & 3 \\
\hline Total & $\mathbf{8 0 0}$ & $\mathbf{1 0 0}$ \\
\hline
\end{tabular}

The information on Table 4 above shows that child abuse may result in a number of problems for victims in relation to their school work. Absenteeism from school and failure to write both school work and home work was cited as the major challenge that children who are abused face $(24 \%)$. Second in the hierarchy of the challenges faced by abused children was obtaining of low marks $(20 \%)$ and sleeping in class was third at $15 \%$. Failure to concentrate, reserveded and timid as well as quiet and shy added up to $27 \%$. Being violent and use of abusive language was at $8 \%$. Finally, those who were said to fondle girls and those who stole other pupils' belongings due to being abused were recorded from $6 \%$ of the respondents at $3 \%$ apiece respectively.

\section{DISCUSSION}

Findings from the study reveal that bullying, physical abuse, child neglect, verbal abuse and sexual abuse are prevalent forms of child abuse in Kwekwe District secondary schools. All the respondents 
indicated that bullying was the most common form of abuse that they experienced. This finding tallies with observations by Schwartz (2009) who states that, younger pupils in secondary schools become victims of bullies who regularly engage in hurtful, teasing, name calling and intimidation which is very difficult to discover by school authorities. Literature also states that emotional abuse, physical abuse and child neglect are the most occurring types of child abuse (Murray, 2010; Denga and Denga, 2007; Wood, 2008 and Reyome, 2013).

Bullying contributes to all these forms of abuses and thus, it constitutes a very dangerous phenomenon in the schools. As Ross (2003) postulates, bullying is widespread and perhaps the most under reported safety problem in school. What makes bullying very bad is that it occurs within the school campus, on the way to school or on the way from school; it is almost everywhere.

The study also reveals that physical abuse is also rampant in the schools understudy. Abusive treatment of children, often misrepresented as discipline, punishment is wrong and dangerous (Merick, 2008). The most common perpetrators of physical abuse in this study were parents or guardians or caregivers, teachers and bullies. Research reveals that children who are physically abused can develop child traumatic stress; they are also at risk for depression and anxiety and child abuse has been linked to poor physical, emotional and mental development (CASA, 2015). Kavishe (2016) describes physical abuse as the use of physical force with the intention of causing the child to experience bodily pain or discomfort so as to correct or punish the child's behaviour. Slapping, spanking, padding and generally hitting for purposes of discipline were the most common forms of physical abuse that children mentioned.

Findings from the study also reveal that children experienced emotional abuse largely from parents/guardians, teachers, siblings as well as bullies. Parents contributed towards emotional abuse through rebuking their children using strong language, fighting in front of children and discouraging children from associating with their friends. Bullies and siblings emotionally abused children by forcing them to take drugs and through use of hate language. Teachers also used strong language to rebuke children and this affected them emotionally. As Ross (2003) posits:

Emotional abuse is the ongoing emotional maltreatment of a child. It is sometimes called psychological abuse and can seriously damage a child's emotional health and development. Emotional abuse can involve deliberately trying to scare or humiliate a child or isolating or ignoring them. Children who are emotionally abused are often suffering another type of abuse or neglect.

The other form of abuse revealed is sexual abuse which is largely perpetrated by bullies and teachers. The findings reveal that some pupils were forced into love affairs and others fondled or molested. Child sexual abuse by teachers appears to be rampant in the schools understudy and yet schools are places where parents send their children to learn. Parents expect those places to be safe and nurturing. Many factors such as unquestioning obedience to authority figures in the school discourage learners from the teacher abusers. This finding tallies with observations by Owuamanan (1995), who argues that there is a high prevalence of sexual abuse in public institutions in most African countries. In Nigeria and in most Africa school setting, the most common place where sexual abuse occurs or takes place is the school (Owuamanan, 1995).

The study also revealed that child abuse has the potential to negatively affect the school work of the victims. Respondents indicated that child abuse was the major cause of absenteeism and failure to write both school and home assignments, sleeping in class, timidness, failure to concentrate, low marks as well as use of violent and abusive language. These findings are congruent with observations by CASA (2015) who posits that studies show that children who have suffered from neglect exhibit lower academic achievement, mistreated children have a greater instance of exhibiting poor social skills and classroom behaviour problems.

\section{CONCLUSION}

Given the background of the above findings; the researcher makes the following conclusions:

- Child abuse from the perspective of the pupils or children themselves, is a very serious phenomenon in secondary schools in Kwekwe District. Unfortunately, schools which society views as safe places for the physical, social, emotional as well as cognitive development of children appear to be failing dismally to protect children from abuse. 
- Bullying is a pervasive cancer that affects many children; and yet in terms of its contribution to child abuse, it has not been viewed as a serious contributor to child abuse. What makes bullying very lethal is that unlike other forms of abuse, it exists where the adult eye cannot see, leaving the victims of the act (bullying) at the mercy of the perpetrators.

- The most prevalent cases of abuse in the schools understudy included physical abuse, emotional abuse, verbal abuse, child neglect and sexual abuse.

- The major perpetrators of child abuse include parents / guardians, bullies in and outside the school, teachers and to some lesser extent siblings.

- Child abuse negatively affects the victims' school work in a number of ways. Pupils fail to effectively do their school or homework; it causes absenteeism, victims become violent and abusive themselves, some become reserved and timid and ultimately, their overall school performance deteriorates.

\section{RECOMMENDATIONS}

In light of the findings of this study, the researcher would like to make the following recommendations:

- School authorities should take child abuse as an inevitable phenomenon that is prevalent in their campuses and subsequently take concrete measures to address the problem

- The Ministry of Primary and Secondary Education is encouraged to promote the use of nonthreatening platforms for children to speak out if they are abused. These could include suggestion boxes within the school premises as well as use of guidance and counselling teachers to encourage children to speak out about their experiences.

- The Victim Friendly Unit of the Zimbabwe Republic Police in collaboration with Non Governmental agencies should collaborate with school authorities to conduct awareness campaigns to discourage would be perpetrators and to give confidence to children so that they could report all forms of abuse.

- Universities and Teacher Education institutions should adequately equip teachers with skills to deal with child abuse issues.

- Local leadership should take it upon themselves to conscientise their subjects about the existence of child abuse and encourage parents to guide their children accordingly.

- There should be stiffer penalties meted on all perpetrators of child abuse to deter would be offenders.

\section{REFERENCES}

[1] Action Aid Zimbabwe (2016). Child abuse exposed. Harare: Action Aid.

[2] Anderson, J. (2015). Sexual abuse. Minnessota: Voices of Children.

[3] Carlson, G. A and Kashani, J. H. (2008). Phenomenology of major depression from childhood through adulthood. The American Journal of Psychiatry (4): 125-139.

[4] CASA (2015). Your time to change a child's life. Harare: UNDP.

[5] Cresswell, J. W. (2009). Research design.

[6] Denga, P. I, and Denga, H. M. (2007). Child parenting in developing nations: Challenges and prospects. London: Rapid Educational Publishers.

[7] Dodge, K. A, and Pettit, G. S. (2004). Effects of physical maltreatment on the development of peer relations. London: Routledge.

[8] Flick, U. (2009). An introduction to qualitative research. London: Sage.

[9] Glensen, B and Peshkin, S. (2012). Recognising and reporting child physical abuse; A survey of primary healthcare professionals. Boston: Maxime Gignon.

[10] Holt, M. K. and Finkelhor (2007). Multiple victimisation. New York: MacMillan.

[11] Iverson, S and Segal, R. (2009). Children and young people disclosing sexual abuse. London: Longman.

[12] Kavishe, T. (2016). Sexual abuse rises as humanitarian cases worsen. Harare: United Nations.

[13] Leedy, P. (2009). Practical research and planning and design. New York: MacMillan. 
[14] Livege, M and Poipoi, S. (2012). Sexual abuse in Georgia. Georgia: The Georgia Legal Services Office.

[15] Mackenzie, N and Knipe, S. (2006). Research dilemmas: Paradigms methods and methodology. Issues in Educational Research, (16): 31-45.

[16] Makoni, B. (2016). Women changing the world. Harare: Girl Child Network.

[17] Marshall, C. and Rossman, B. G. (2006). Designing qualitative research. Forum: qualitative social research, (9): 15-26.

[18] Mapolisa, T. (2015). Cases of child abuse in schools. Harare: Zimbabwe Open University.

[19] Mfonobong, E. U. (2013). Child abuse and its implications for the educational sector in Nigeria. National Policy on Education. Lagos: federal Government Press.

[20] Moyo, B. (2015). Child abuse and neglect. Harare: Mambo Press.

[21] Mpofu, W. (2008). Child abuse: Everyone's; responsibility. Harare: ZPH.

[22] Murimba, B. (2009). Curbing physical violence. Harare: Zimbabwe Open University.

[23] Ndlovu, B. (2016). Children abuse. Cancer in the homes. Harare: Mambo Press.

[24] Ndlovu, P. (2016). Child abuse in Zimbabwe. Harare: ZPH.

[25] Razaviah, A. (2010). Introduction to research in education. London: Routledge.

[26] Reyome, R, Bosswell, J, (2013). The kindness of strangers. The abandonment of children in Western Europe.

[27] Rupapa, T. (2016). Child abuse spike worrying. Harare: The Herald.

[28] Smith, T. (2014). Preventing child abuse. New York: Longman.

[29] Shonk, S. M and Acchetti, D. (2001). Maltreatment, comp.

[30] Wood, M. (2008). The nurture assumption: Why children turn out the way they do. New York: Vintage.

\section{AUTHORS' BIOGRAPHY}

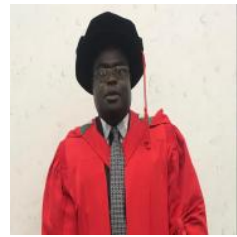

Dr Wilard Nyathi, an academic, administrator, manager and an author. A holder of a $\mathrm{PhD}$ in educational leadership, Management and policy development, $\mathrm{M} \mathrm{Ed}$ in educational leadership and Management, MBA in business leadership and Management, B Ed Management, Diploma in education and Diploma in Information Technology

Citation: Willard Nyathi. "The Impact of Child Abuse in Kwekwe District Secondary Schools in Zimbabwe" International Journal of Humanities Social Sciences and Education (IJHSSE), vol 7, no. 9, 2020, pp. 120-127. doi: https://doi.org/10.20431/2349-0381.0709012.

Copyright: (c) 2020 Authors. This is an open-access article distributed under the terms of the Creative Commons Attribution License, which permits unrestricted use, distribution, and reproduction in any medium, provided the original author and source are credited. 